\section{Artritis séptica por Escherichia coli en una mujer con artropatía gotosa}

\section{Sr. Director:}

Debido a las dificultades inherentes a su diagnóstico, la coexistencia de artritis séptica y artritis microcristalina ha sido descrita en pocas ocasiones en la literatura médica (1-6), predominando las desarrolladas en pacientes con artropatía por pirofosfato cálcico (2). Staphylococcus aureus y el género Streptococcus son los principales agentes etiológicos de las artritis infecciosas, tanto en España $(7,8)$ como en otros países (9), y suponen conjuntamente más del $60 \%$ de los aislamientos. Por el contrario, Escherichia coli representa menos del $7 \%$ de las artritis bacterianas de los adultos (7-9) y, en nuestro conocimiento, sólo se ha descrito asociado con artritis microcristalina en cuatro ocasiones $(2,4)$. Por estos motivos consideramos de interés la presentación de una paciente con artropatía gotosa que sufrió una artritis séptica por $E$. coli en la rodilla izquierda.

Paciente de 67 años con antecedentes de fractura de tibia y peroné izquierdos durante su juventud, hipertensión arterial tratada con diuréticos desde hacía 17 años e hiperuricemia, que ingresa en nuestro servicio de reumatología por artritis de rodilla izquierda y fiebre. Estos síntomas se habían iniciado diez días antes de forma aguda, tras una infección urinaria por Escherichia coli, y habían persistido pese al tratamiento con diclofenaco oral a dosis de $150 \mathrm{mg} /$ día.

En la exploración destacaba el aumento de temperatura en la rodilla izquierda asociado a un abundante derrame y dolor con la movilización, engrosamiento sinovial e impotencia funcional en la muñeca izquierda, hepatomegalia de $3 \mathrm{~cm}$, sequedad de mucosas, palidez cutánea y fiebre de $38,3^{\circ} \mathrm{C}$. Asimismo se observaban depósitos tofáceos en los dedos de las manos y de los pies. La artrocentesis de la rodilla izquierda dio salida a un líquido purulento (180.000 células $/ \mathrm{mm}^{3}$ con predominio de neutrófilos: 95\%) en el que, además, mediante microscopía con luz polarizada, se visualizaron cristales aciculares intracelulares de fuerte birrefringencia y elongación negativa, compatibles con urato monosódico. Con la tinción de Gram se observaron bacilos gramnegativos que posteriormente se recuperaron en el cultivo y se identificaron como Escherichia coli. En la muñeca izquierda se obtuvieron 0,5 cc de líquido articular que mostraba abundantes cristales de urato pero cuyo cultivo fue negativo. La enferma fue tratada con cefotaxima ( $1 \mathrm{~g} / \mathrm{IV} / 8 \mathrm{~h})$ durante 6 semanas).

Los análisis mostraron una VSG de $139 \mathrm{~mm} / 1^{\mathrm{a}} \mathrm{h}$, anemia $(\mathrm{Hb}$ : $81 \mathrm{~g} / \mathrm{L})$ normocrómica y normocítica, leucocitosis $\left(24,2 \times 10^{9} / \mathrm{L}\right.$; $87 \%$ neutrófilos y $4 \%$ cayados $)$, plaquetas $\left(366 \times 10^{9} / \mathrm{L}\right)$, urea (132 mg/dl), creatinina $(2,2 \mathrm{mg} / \mathrm{dl})$, ácido úrico $(8,5 \mathrm{mg} / \mathrm{dl})$, ASAT (74 U/L), ALAT (33 U/L), sideremia (24 mg/dl). Las determinaciones de glucosa, fosfatasa alcalina, colesterol total, triglicéridos, calcio, fósforo y estudio de coagulación fueron normales. Tanto el urocultivo como los tres hemocultivos seriados realizados al ingreso fueron negativos. En el proteínograma se objetivó una hipergammaglobulinemia de 2,3 g/dl con características monoclonales: IgM (126 mg/dl), IgA (234 mg/dl), IgG (2.140 mg/dl; cadenas ligeras lambda: 902 mg/dl, Kappa: 1.766 mg/dl). FR (látex), ANA y anticuerpos anti-DNA negativos. La excreción urinaria de urato en 24 horas fue de $254 \mathrm{mg}$.

Se efectuaron radiografías de las manos, pies, rodillas y tórax. En los carpos, metacarpofalángicas y metatarsofalángicas se objetivaron erosiones típicas de la artropatía gotosa. Las rodillas mostraban disminución de la interlínea articular, afilamiento de las espinas tibiales y pequeños osteofitos marginales; además, la rodilla izquierda presentaba un aumento de volumen y densidad de sus partes blandas, con incipientes erosiones en las superficies óseas del compartimiento interno. Una ecografía abdominal puso de manifiesto una moderada hepatoesplenomegalia. Se practicó aspirado y biopsia de médula ósea cuyo estudio histológico fue de características reactivas; adicionalmente, la tinción con Rojo Congo resultó negativa.

El hemograma practicado al tercer día de estancia hospitalaria mostró anemización ( $\mathrm{Hb}$ : $69 \mathrm{~g} / \mathrm{L}$ ), por lo que se realizó una endoscopia digestiva alta en la que se observó una gastritis erosiva antral con signos de sangrado reciente. Al tratamiento antibiótico y los lavados articulares diarios se añadió omeprazol (20 mg/día), antiácidos orales y, posteriormente, alopurinol. Los cultivos del líquido articular se negativizaron a partir del cuarto día de antibióticoterapia y la enferma evolucionó favorablemente. No fue necesaria medicación para el control de la presión arterial. En el momento del alta, presentaba dolor mecánico y limitación de la flexión de la rodilla a $85^{\circ}$; además, los análisis mostraban $\mathrm{Hb}(101 \mathrm{~g} / \mathrm{L})$, creatinina $(1,6 \mathrm{mg} / \mathrm{dl})$, ácido úrico $(5,95 \mathrm{mg} / \mathrm{dl}) \mathrm{e}$ $\operatorname{IgG}(1.604 \mathrm{mg} / \mathrm{dl})$.

La uricemia en la mujer se incrementa a partir de la menopausia y el riñón es su principal determinante, pues elimina aproximadamente el $75 \%$ de la cantidad de urato sintetizada diariamen- 
te. En edades avanzadas, el uso de diuréticos, que reducen la uricuria, es una causa de hiperuricemia y gota en ambos sexos (10). Nuestra paciente era hipertensa, había sido tratada con diuréticos durante 17 años y presentaba una gota tofácea. La mayoría de los autores coincide en interpretar al proceso infeccioso como desencadenante de la artritis microcristalina $(1,2)$. Así, los cristales serían movilizados de sus depósitos articulares por las enzimas lisosómicas de los leucocitos polimorfonucleares durante la fagocitosis bacteriana. Además, el incremento del $\mathrm{pH}$ articular reduciría la solubilidad del urato monosódico y provocaría su precipitación. Por otra parte, el daño articular inducido por el depósito de microcristales y los cambios degenerativos propios de la edad son factores favorecedores para el asentamiento de microorganismos patógenos en caso de bacteriemia, que, en nuestra paciente tuvo probablemente su puerta de entrada en las vías urinarias.

Aunque la asociación de artritis séptica y microcristalina no constituya una situación clínica frecuente, la similitud de las manifestaciones articulares en ambos procesos obliga a ser cauteloso y, a pese a la visualización de cristales, debe llevarnos a excluir la complicación infecciosa mediante la realización de la tinción de Gram y el cultivo de líquido sinovial (2).

\section{N. Gómez Rodríguez, J. Ibáñez Ruán, M. González Pérez}

Unidad de Reumatología. Colón-28 Clínica. Vigo

1. Baer P A, Tenenbaum J, Fam AG, Little H. Coexistent septic and crystal arthritis. Report of four cases and literature review. J Rheumatol 1986; 13: 604-607.

2. Batlle E, Tovar J V, Pascual E, Salas E. Artritis séptica con microcristales: una causa de error diagnóstico. Med Clin (Barc) 1987; 89: 281-284.

3. Ibáñez J, Ballina J, Queiro R, Rodríguez A. Condrocalcinosis y artritis séptica. Rev Esp Reumatol 1992; 19: 249-350.

4. Ilahi O A, Swarna U, Mail R J, Young E J, Tullos H S. Concomitant crystal and septic arthritis. Orthopedics 1996; 19: 613-617.

5. Daroca R, San Roman F J, Mosquera J D, Lantero M. Artritis séptica brucelar con microcristales. Rev Esp Reumatol 1993; 20: 140-141

6. Pérez D, Olivé A, Tena X. Coexistencia de artritis infecciosa y artritis microcristalina. An Med Intern 2000; 17: 329-330.

7. Belzunegui J, Plazaola I, Maíz O, López L, González C, Figueroa M. Artritis infecciosas no tuberculosas en Guipúzcoa. Presentación de 83 casos. Rev Esp Reumatol 1997; 24: 209-212.

8. Del Val del Amo N, Erausquin C, Blanco R, Pinillos V, Martínez V, Rodríguez V. Estudio de 112 pacientes con artritis séptica por piógenos y hongos: cambios en el espectro clínico durante las dos últimas décadas. Rev Clin Esp 1997; 197: 540-544.

9. Le Dantec L, Maury F, Flipo R M, Laskri S, Cortet D, Dusquesnoy B, Delcambre B. Peripheral pyogenic arthritis. A study of one hundred seventy-nine cases. Rev Rhum (Engl Ed) 1996; 63: 103-110.

10. E. Pascual. Gota. En, Pascual E, Rodríguez V, Carbonell J, Gómez-Reino J J, eds. Tratado de Reumatología. Tomo II. Madrid, Aran Ediciones SA, 1998; pp: 1.461-1.475.

\section{Hepatitis aguda asociada a la combinación de amoxicilina-ácido clavulánico}

\section{Sr. Director:}

La combinación de amoxicilina y ácido clavulánico es un fármaco de extendido uso clínico de la que se conoce sus efectos adversos entre los cuales, de forma infrecuente, se encuentra su efecto tóxico hepático sobre todo de características colestásicas siendo más raramente su efecto tóxico hepatocelular (1). El empleo de la combinación de la amoxicilina y el ácido clavuláni- co en el tratamiento de las infecciones más comunes de origen bacteriano está ampliamente extendido en la práctica clínica, debido a su amplio espectro bacteriano y a su eficacia clínica demostrada. La frecuencia de sus efectos adversos se ha estimado entre 4-14\%, constituyendo en el $90 \%$ de ellos a episodios leves o moderados, los cuales corresponden a episodios de diarreas, sensación de náuseas o vómitos y reacciones cutáneas; la hepatotoxicidad asociada al empleo de amoxicilina/clavulánico es un hecho infrecuente con incidencia aproximada de 1 de 200.000 prescripciones según datos publicados en la literatura (2). El mecanismo patogénico implicado no esta suficientemente aclarado, aunque la asociación de hepatitis con evidencia de hipersensibilidad sugiere un mecanismo inmunoalérgico $(3,4)$.

Se trata de un varón de 77 años con antecedentes de temblor esencial en tratamiento con primidona e HTA en tratamiento con IECAs de larga evolución, que ingresa por infección de origen respiratorio por lo que se inicia tratamiento con Amoxicilina/clavulánico a dosis de $2 \mathrm{~g}$ por vía endovenosa cada 8 horas. En la exploración física destaca a la auscultación pulmonar abundantes roncus bilaterales; el ECG y la radiografía de tórax no aportan datos reseñables; en la analítica de sangre del ingreso se observa discreta leucocitosis con ligero predominio de neutrófilos siendo el resto de hemograma y bioquímica normales (ASAT $18 \mathrm{U} / \mathrm{L}$; ALAT $20 \mathrm{U} / \mathrm{L}$; bilirrubina total $0,9 \mathrm{mg} / \mathrm{dL}$ ). A los 4 días de iniciado el tratamiento antibiótico presenta leve ictericia mucocutánea por lo que se solicita analítica de sangre donde se objetiva ASAT 908 U/L (normal 0-18), ALAT 1.958 U/L (normal 0-22), Bilirrubina total 2,7 mg/dL (normal 0-1,1), Bilirrubina directa 1,7 $\mathrm{mg} / \mathrm{dL}$ (normal 0-0,4) y fosfatasa alcalina $103 \mathrm{U} / \mathrm{L}$ (normal 40129); la serología de hepatitis víricas A, B y C fueron negativas. Se suspende Amoxicilina/clavulánico cambiándose por otro antibiótico (cefotaxima), se inicia tratamiento con S-adenosilmetionina y se solicita TAC Abdominal donde se observa un hígado de tamaño normal con parénquima de densidad homogénea. En la analítica de sangre de control a los 7 días se objetiva ASAT 32 U/L, ALAT $188 \mathrm{U} / \mathrm{L}$, Bilirrubina total 1,9 mg/dL, Bilirrubina directa $1,0 \mathrm{mg} / \mathrm{dL}$ y FALC 96 . El paciente fue dado de alta con evolución favorable, encontrándose asintomático.

La hepatotoxicidad asociada al empleo de la combinación de Amoxicilina/clavulánico es un efecto adverso infrecuente en los descritos en la literatura por el uso ampliamente extendido de dicho antibiótico $(1,2)$. No es claro si la toxicidad se debe exclusivamente al ácido clavulánico o a la interacción de este con Amoxicilina, aunque la frecuencia de reacciones adversas es claramente mayor con la combinación de ambos que con el uso de Amoxicilina sola (3). Estimaciones realizadas a partir de los datos publicados en la literatura señalan que la incidencia aproximada de hepatotoxicidad por este antibiótico es de 1 por 200.000 prescripciones (4). El factor predisponente más importante lo constituye la edad, más frecuente en pacientes mayores de 65 años, siendo otro factor de menor relevancia la exposición prolongada al mencionado antibiótico. La patogenia de las lesiones y de las manifestaciones clínicas de la hepatotoxicidad por el mismo no está aclarada, aunque la asociación de hepatitis con evidencias de hipersensibilidad sugiere un mecanismo inmunoalérgico. Se han descrito tres mecanismos de hepatotoxicidad: Colestasis, lesión hepatocelular y mezcla de ambas (5-7). La forma clínica más frecuente ( $75 \%$ casos) corresponde a la aparición de un síndrome colestásico (7) caracterizado por una marcada elevación de los niveles de bilirrubina sérica y de la actividad de fosfatasa alcalina y la gamma-glutamil-transpeptidasa; la aparición de hepatitis con una elevación predominante de los niveles séricos de transaminasas es una forma de presentación rara (8). En algunos casos se ha reralizado biopsias hepáticas para confirmar el diagnóstico y valorar el grado de afectación. El inicio de aparición de los síntomas es variable (rango 2-45 días). La clínica predominante es la ictericia y, en menor medida, prurito, no guardando este relación directa con el grado de colestasis. En algunos 